\title{
Good Will and Confidence
}

In the July 1974 issue of this journal, Michael Bommer and Bernard Ford discussed the uncalculated expense a library incurs through its inability to serve when it cannot produce a document it is supposed to have or obtain a replacement for one lost through theft. They term this cost "good will or confidence."

In a related article in the September issue, Jay B. Clark pointed out how readers at the Houston Public Library had lost confidence in that library's catalog because it no longer accurately reflected the library's holdings. This fact prompted the library to inventory its collections and remove cards from the catalog for items no longer present.

A different viewpoint of this subject is given in the current issue. In their article "Project Library Ripoff," Clyde Hendrick and Marjorie E. Murfin summarize students' views on the mutilation of library materials. The thoughts they present are disquieting-if not surprising: for example, the students in their study do not consider mutilation a serious offense. They are not much concerned about being caught if they do mutilate materials; nor would they act if they saw someone else mutilating a book or periodical. Coupled with these thoughts is the general widespread underestimation by the students of the cost and effort needed to replace or repair multilated items.

To cope with this problem, Hendrick and Murfin recommend a major program of information for library users. The program, to be repeated periodically, would emphasize the financial costs our institutions incur through mutilation. Additionally, they recommend warning signs and unobtrusive surveillance in critical areas of the library. Bommer and Ford's article is directed toward a more impersonal form of surveillance designed to discourage theft-the use of an electronic security system.

We have thus seen that there are two aspects to "good will and confidence"-readers, with that uncertain feeling, not sure the items they wish will actually be on the shelves or otherwise available, and library staff undertaking programs of information and installing security devices to protect the material under their care. Each group suffers from this loss of good will and confidence. With that knowledge, however, we can approach our daily tasks with more realistic expectations and do the best job we can. 